\title{
La teoría crítica de la lingüística entre las ciencias de la cultura y las ciencias cognitivas, y las bases biológicas del lenguaje
}

\begin{abstract}
Una tarea básica de la "Teoría crítica de la Lingüística" es revisar los criterios de validez epistemológica desde los que se acuñan y juzgan los conceptos de la lingüística, para lo cual es necesario integrar los progresos de la "filosofía crítica" de Kant, Hegel y otros. A la luz de esa filosofía se examinan la ampliación del objeto lingüístico hacia las actuales "ciencias de la cultura" por un lado, y el reduccionismo desde el que se plantean los abordajes cognitivistas del lenguaje por el otro. Sigue una breve exposición de los resultados más relevantes de las modernas neurociencias para la lingüística, en particular de las nociones de complejidad emergente, dinamicidad e individualidad tanto anatómica como de la conectividad. Se añade como apèndice una primera aproximación crítica a las tesis cognitivistas de Steven Pinker.
\end{abstract}

\section{Palabras clave}

crítica epistemológica de los conceptos lingüísticos, lenguaje y ciencias de la cultura, reduccionismo en la lingüística cognitiva, bases neurológicas del lenguaje.

\begin{abstract}
One basic task of the "Critical Theory of Linguistics" is to develop criteria of epistemological validity for creating and judging linguistic concepts. The German "critical philosophy" of Kant, Hegel and others furnish the main tools for the criticism of the recent expansion of the linguistic object towards modern "cultural sciences", as well as of the reductionism governing current cognitive approaches. A brief summary of the most relevant results of contemporary neural sciences for linguistics follows, focusing mainly on the notions of emergent complexity, dynamics and individuality both at the anatomical level and at the shaping of connectivity. In an appendix a first critical approach to Steven Pinker's cognitivistic theses is presented.
\end{abstract}

\section{Keywords}

epistemological criticism on linguistic concepts, language and cultural sciences, reductionism in cognitive linguistics, neural base of language.

\section{Introducción}

Hacia el final del siglo XX la idea de que el lenguaje constituye por sí mismo una especie de objeto natural de la ciencia ha perdido su evidencia, y se ha agotado esa "ideología gramatical" que contempla como lo esencial del lenguaje una gramática fundamentalmente

* Ana Agud, nacida en 1948 en San Sebastián, licenciada en 1970 en Filología Clásica en Salamanca, doctorado en 1976 en Salamanca bajo la dirección de E. Coseriu sobre "Historia y teoría de los casos". Desde 1978 Prof. Titular de Lingüística Indoeuropea en Salamanca. 1989-90 becaria de la Fundación Humboldt en Bonn.

Libros: Historia y teoría de los casos, Madrid 1981; Manual de lengua gótica, Publ. de la Univ. de Salamanca, 1982, reed. 1988, 263 p., L.; Pensamiento y cultura en la antigua India, Akal, Madrid 1996; La ciencia del Brahman: Once Upanishad antiguas. Traducción comentada. Madrid 2000. Altindische Weisheiten (Traducción al alemán de una selección de textos de las Upanishad indias), Colonia 2008.

Artículos sobre lingüística teórica y filosofía del lenguaje y de la lingüística; Indología (sobre todo literatura védica y clásica, filosofía y teoría del lenguaje indias), Indoeuropeo, teoría de la traducción, estética y teoría de la literatura, lenguaje y música, estudio comparativo de las culturas.

Docencia sobre Indoeuropeo, Indología, teoría del lenguaje, ciencias de la cultura. Directora del programa "Experto universitario en lenguas y culturas de India e Irán" de la Universidad de Salamanca. 
identitaria y generadora de identidad; que pone en primer plano el elemento puramente verbal del hablar como si fuese un objeto autónomo, y que intenta definirlo y describirlo como si fuese algo que existe tangiblemente y con perfiles propios. En el presente artículo, que continúa a uno anterior publicado en esta misma revista, quisiera abordar las razones de este cambio desde la perspectiva de una "Teoría o filosofía crítica de la Linguiística" actualmente en proceso de elaboración.

\section{La crisis de la ideología gramatical y el cultural turn en las ciencias humanas}

\subsection{El déficit pragmático de los modelos teóricos de la descripción lingüística}

Ya la lingüística histórico-comparativa representa en el siglo XIX una cierta interrupción de esta ideología. La nomología en la evolución de los sonidos del lenguaje que ella descubre, con su naturaleza casi naturalcientífica, sólo opera reconocidamente en tiempos y lugares precisos, y no es independiente de otros niveles de la articulación de la expresión. Factores morfológicos y sintácticos, pero también motivaciones sociales y políticas contribuyen ocasionalmente a la fisonomía sonora de un texto. Un ejemplo: investigaciones recientes en el campo de los textos indios antiguos muestran cómo ciertas ideologías asociadas a la política de poder contribuyeron a una marcada sanscritización de ciertos textos litúrgicos en nuevas regiones más orientales, en las que los nuevos gobernantes se esforzaban por hacerse con una legitimidad védico-brahmánica. De este modo algunas peculiaridades fonéticas de esos textos resultan estar condicionadas por pretensiones sociopolíticas. Los sonidos son, por así decirlo, el rostro de las lenguas, y con ellos también se pueden hacer "muecas".

En definitiva la lingüística histórico-comparativa alentó un abordaje holístico del lenguaje: se trataba de entender formas y textos, tanto en su forma como en su sentido, por referencia a otras formas y textos tanto de la misma lengua como de otras emparentadas con ellas o en contacto cultural más o menos estrecho. Esto supone aceptar una estrecha interrelación entre todos los posibles aspectos de una cultura y entre todas las posibles estructuras y motivaciones en cada hablante o escritor. De esta orientación nació, sobre todo en Alemania, el moderno concepto holístico de las filologías idiomáticas como verdaderas ciencias culturales.

Sin embargo la corriente principal de la Lingüística del siglo XX discurrió ante todo en el sentido de erigir modelos generales y abstractos del lenguaje, que articulaban éste en módulos estructurales netamente delimitados entre sí y bastante independientes unos de otros. Estos modelos se confeccionaron casi exclusivamente sobre la base de lenguas vivas.

La idea de que la tarea de la lingüística sea la descripción de lenguas se tomó de las ciencias de la naturaleza, en las cuales la descripción de lo que hay está al servicio de su dominio y manipulación técnicas. Ahora bien, desde el momento en que todo hablante domina su lenguaje desde el principio, la pura descripción de las lenguas vivas carece de la justificación pragmática usual en las ciencias naturales. Y a más tardar desde Kant estamos suficientemente ilustrados sobre el decisionismo inherente a toda descripción puramente "teórica" o contemplativa en el campo de las ciencias humanas ${ }^{1}$.

1 Para una crítica epistemológica pormenorizada a la lingüística modelizadora del siglo XX cfr. Ana Agud, "Virtuelle und faktische Sprache: eine Linguistik der Faktizität als philosophische Disziplin", Allgemeine Zeitschrift für Philosophie18.3, 1993, pp.17-41. 


\subsection{Estatuto epistemológico de las categorías de la descripción lingüística}

La descripción lingüística, en el sentido usual del término, se propone categorizar los fenómenos lingüísticos bajo conceptos más o menos jerarquizados, bajo los cuales se supone que se pueden subsumir las presuntas unidades o formaciones lingüísticas, como casos o exponentes de esas categorías. ¿Pero cómo se origina una categoría lingüística?

Como todo en el "lenguaje coloquial": gracias a una ocurrencia. Cada investigador contempla el presunto objeto de su disciplina, presuntamente identificado por el vocablo "el lenguaje", desde la perspectiva que le es usual, y se hace las preguntas que se le ocurren, por ejemplo: ¿qué es el lenguaje? ¿Qué es la sintaxis? ¿Qué es una frase, un texto, una palabra, un caso, un significado? A esta clase de preguntas cada uno responde a partir del conjunto de su experiencia y de la formación de su personalidad en el momento, y lo hace con las palabras que le resultan familiares, o bien con otras que inventa se acuerdo con las pautas de formación de palabras de su idioma. Es así como han visto la luz términos hoy habituales como fonema, morfema, semantema, textema, autorema, etc.

A más tardar a partir de Kant y de Hegel habríamos tenido a nuestra disposición las herramientas necesarias para criticar filosóficamente las pretensiones de validez epistemológica de este tipo de categorizaciones espontáneas, pero se buscará en vano una reflexión metodológica dentro de la linguiística que tome pie en las críticas kantianas o en la Fenomenología y la Lógica de Hegel. La mayoría de los lingüistas da por sentado que sus palabras se refieren a la realidad y la aprehenden y organizan con la debida objetividad, así que no duda de la objetividad de designaciones como fonema, caso o sintagma, a pesar de que cada escuela usa estas palabras a su manera, y de que se dan profundas discrepancias de sentido y referencia entre ellas.

\subsection{Nuevas tendencias analíticas: las ciencias de la cultura y de la cognición}

La falta de una reflexión crítica sobre sus propios conceptos y sobre la manera de llegar a ellos alentó en la Lingüística del siglo XX una multiplicación descontrolada de escuelas y tendencias que acabó por arrojar sobre la lingüística en su conjunto una fuerte sospecha de arbitrariedad, análoga a la que ya pesaba sobre la filosofía. De entre esta pluralidad, en la que obviamente sobrevivían también las viejas formas de descripción gramatical, sobresalen ahora por su protagonismo tres nuevas tendencias: la lingüística computacional, la lingüística cognitiva y la lingüística del texto.

La lingüística computacional es una pura tecnología lingüística, de modo que queda fuera de las ciencias humanas y su problemática.

La lingüística cognitiva es parte de las llamadas "ciencias cognitivas", que indagan mediante procedimientos experimentales controlados la fenomenología de lo que llaman la "mente", signifique esto lo que signifique. En este contexto el lenguaje se aborda como una forma de comportamiento. Se lo investiga según las pautas de la psicología experimental, que con metodología reduccionista descompone los comportamientos en componentes mínimos y reconduce éstos a parámetros mensurables en experimentos. Se mide por ejemplo cuánto tiempo retienen en la memoria los sujetos de experimentación secuencias de sonidos, sílabas o palabras bajo modificaciones controladas del contexto. O se observa qué zonas del cerebro se iluminan mientras los sujetos resuelven tareas con sonidos, palabras o frases bajo control de aparatos de neuroimágenes. O se recuenta cuántos sujetos de una población estadística prefieren una u otra opción en tests sobre todo lo imaginable: desde la atracción o aversión 
emocionales hacia determinadas expresiones hasta los tiempos de reacción a formaciones sintácticas sometidas a tal o cual modificación o distorsión. El campo es infinito. La actividad está blindada metodológicamente. La problemática epistemológica de la formación de conceptos puede volver a eludirse. Volveremos sobre esto.

Por su parte la nueva lingüística del texto ha desdibujado ampliamente la frontera artificial entre linguiística y filología y exhibe un alegre pluralismo metódico: los lingüistas del texto en la actualidad investigan todo posible texto para cualquier objetivo posible y con cualquier método posible. Esta linguística del texto emancipada de cualquier coerción metodológica se ha ido aproximando a esas "ciencias de la cultura" nacidas de ciertas escuelas de teoría de la literatura, cuyo principal vector es la preocupación por los miembros o grupos subprivilegiados de las sociedades modernas. Las ciencias de la literatura y del lenguaje convergen aquí en su interés prioritario por las formas de expresión de la discriminación, de la marginalización, de la estigmatización y de todo tipo de conflictos sociales y culturales. Por eso la lingüística del texto actual se ocupa sobre todo de textos que quedan fuera del llamado "canon" literario, y analizan comics, videojuegos, publicidad, prensa, conversaciones casuales y todo tipo de literatura de consumo, con el fin de rastrear por ellos los reflejos de los prejuicios sociales e ideológicos.

De este modo la preeminencia teórica de la ideología gramatical identitaria como guía de la lingüística se ha venido abajo más o menos silenciosamente. En este nuevo escenario el lenguaje apenas interesa ya como una estructura en sí. Interesa ante todo el uso social e ideológico sobre todo del vocabulario en los textos de las diversas culturas, y la disciplina que se ocupa de ello se entiende a sí misma más bien como una semiótica. Pero lo que más interesa son las propias culturas, la comunicación entre ellas, el intercambio religioso, la convivencia de los grupos sociales con sus culturas grupales, etc., El linguistic turn parece haber concluido, y en su lugar asistimos a un nuevo cultural turn, al que la justificación epistemológica de su vocabulario, de sus axiomas ampliamente inconscientes y de la formación de sus conceptos le procupa igual de poco que a su antecesor lingüístico.

Este giro cultural reproduce en el fondo toda la estructura de prejuicios de las ciencias cientificistas de la literatura y el lenguaje. Comparte con ellas esa confianza inmediata en la adecuación objetiva de sus categorías descriptivas, ignora que se mueve en un círculo hermenéutico, y vuelve a edificar modelos de una presunta realidad cultural que son tan decisionistas como los linguiísticos. El hecho de que el campo de sus objetos parezca más extenso y abarcante que el de la linguística basta para justificar el sentimiento de que éste es por fin el verdadero objeto de las ciencias humanas.

Este nuevo objeto aspira a abarcar el conjunto de lo que Hegel llamaba las "objetivizaciones" sociales del espíritu humano, y junto a su tratamiento disciplinar se está intentando abordar el espíritu mismo de un modo análogo al de la psicología del siglo XIX: como una "mente" asequible a la investigación empírica, y que debe ser objeto tanto de las neurociencias como de la psicología experimental, por más que en la escena académica los que se ocupan de él son más bien los llamados "cognitivistas". Estos se presentan ahora como los nuevos expertos en subjetividad humana.

Frente a esta fragmentación espontánea de las ciencias humanas en culturales y cognitivas quisiera en lo que sigue desarrollar algunos aspectos de una alternativa que, como ya he expuesto en ocasiones anteriores, parte del primer giro lingüístico del pensamiento occidental, el de Humboldt, y aborda la condición linguística de la especie humana, desde una perspectiva crítica, como una condición general de la humanidad, pero entendiendo ésta no 
como un supuesto de hecho sino como una tarea ética. Este planteamiento toma en consideración el papel del lenguaje en toda formación de conceptos, tanto cultural como científica. Quisiera además integrar en esta reflexión los progresos recientes en la exploración del cerebro humano, con el fin de mejorar la comprensión de esa misma condición lingüística.

\section{Las bases biológicas del lenguaje: individualidad, temporalidad y dinámica del cerebro humano.}

La investigación contemporánea del sistema nervioso no sólo de la especie humana, sino a lo largo del conjunto de la escala evolutiva, apoya inequívocamente planteamientos alternativos al de la ideología gramatical identitaria. Es cosa ya comprobada que el complejo centro de control de todas las funciones vitales que es el cerebro no trabaja en centros funcionales netamente delimitados entre sí. Las áreas cerebrales más o menos inequívocamente relacionadas con determinadas actividades trabajan en una interconexión extremadamente densa. Las teorías actuales sobre la conciencia, todas ellas aún especulativas y tentativas, parten del hecho de que nuestro sistema nervioso exhibe una conectividad única entre los seres vivos. Lo que hace del cerebro humano la estructura más compleja de la que se tiene noticia en el universo conocido es menos el carácter muy diferenciado de sus estructuras celulares, o la cifra astronómica de células que contiene, que la complejidad emergente que genera esa conectividad interna.

Quisiera en lo que sigue concentrarme en algunos pocos hechos importantes. En primer lugar quiero señalar el carácter complementario de dos tipos de procesos neurales.

Por una parte la ruta de las señales neurales desde los órganos de los sentidos hasta el córtex asociativo constituye un proceso convergente, por el cual la gigantesca pluralidad de señales singulares es filtrada en centros de relevo sucesivos, por un juego sutil de neuronas excitatorias e inhibitorias, de modo que las señales más débiles y escasas se descartan y las más fuertes y frecuentes se refuerzan. De este modo la multiplicidad inicial de las sensaciones va siendo objeto de una simplificación progresiva.

A partir de un cierto punto, específico para cada sentido, estas señales ya simplificadas y magnificadas son primero coordinadas entre sí, esto es, diversas señales visuales por ejemplo se coordinan de modo que a partir de las señales singulares se produzca una imagen coherente. Luego estas imágenes o representaciones se coordinan con las de otros órganos de los sentidos, así como con las de la llamada "propiocepción", y finalmente se las asocia a recuerdos tanto de ese campo sensorial como de los otros, así como con procesamientos tanto conscientes como sobre todo inconscientes de todo ello. Este procesamiento asociativo de las señales sensoriales genera continuos feedbacks, de modo que la percepción consiste en un constante ir y venir de señales primarias y resultados de procesamientos complejos de las mismas.

En la actualidad la "propiocepción" se considera también como un sentido. La elaboración de las señales sensoriales recibe continuos feedbacks sobre la posición, movimientos y postura del cuerpo por referencia a lo que se percibe, sobre la posición y movimiento de los propios miembros, sobre estados interiores del sistema nervioso y sobre todo tipo de parámetros biológicos: tensión arterial, balance hormonal, etc. De este modo la "posición" y "perspectiva" del individuo por referencia a lo que percibe y a cómo lo percibe son integradas de continuo en la propia percepción.

Nuestro cerebro construye así sus imágenes sensoriales y sus elaboraciones como representaciones endógenas. Estas no son simples reflejos de cosas exteriores, sino resultados 
de nuestra interacción corporal con ellas. Como dice Antonio Damasio, algo provocativamente, "mind is about the body", . Ahora bien, al parecer estos procesos no arrojan productos que se almacenen de uno u otro modo. Nada queda realmente almacenado. Lo que sentimos, recordamos, decimos y pensamos es el resultado momentáneo del acceso a la conciencia de algunos procesos singulares a partir de un incesante e infinitamente diferenciado "panta rei" neural, que consiste en billones de sinapsis en curso. Nadie sabe cómo emergen de esta masa los procesos que devienen conscientes y de los que nos damos cuenta.

Es cierto que en todos los individuos las neuronas de cada área y estrato proyectan básicamente hacia las mismas otras áreas y estratos, y que esta base de proyecciones homogéneas es heredada. Sin embargo, y más allá de estas proyecciones locales constantes, las señales recorren en cada individuo grandes circuitos neurales, los llamados "global maps", que pueden ser y son de hecho muy distintos de un individuo a otro. Los diversos inputs neurales procedentes de las experiencias individuales producen un reforzamiento de unos circuitos neurales y no de otros, y este reforzamiento se asocia a la emisión de nuevos terminales sinápticos en los axones de las neuronas presinápticas. Surge de este modo una huella anatómica individual de las experiencias y de sus elaboraciones, que condiciona circuitos propios en cada individuo y que además se está modificando también continuamente. Y parece que esta activación repetida y por eso mismo reforzada de determinados circuitos sinápticos en recorridos más o menos largos es lo único que "está ahî" o que "queda".

Al hablar y no callar se produce una compleja actividad motora global, que implica a numerosas partes del cuerpo, y que se controla neuralmente de forma que, entre otras cosas, surge un flujo vocal que en su mayor parte se atiene a pautas verbales previas, tanto activas como pasivas, y las repite, por más que la mayor parte de lo que se dice, y tal como se lo dice, no es enteramente idéntica a ninguna otra dicción. Lo que en definitiva se manifiesta como actividad motora fonatoria, pero no sólo fonatoria, es en cada caso el resultado de una coordinación no sólo de muchas clases de recuerdos (verbales, motores, sensoriales, pero también cognitivos, de experiencias y de expectativas de todo tipo), sino también de continuos feedbacks propioceptivos y comunicativos, así como de todo tipo de disposiciones genéticas y epigenéticas que a su vez se adaptan y modifican bajo un constante control de retroalimentación. Los circuitos que recorren las señales en todo este proceso son nuevamente del orden de billones.

Estos procesos neurales se caracterizan por ser degenerativos y redundantes. Degenerativos: la mayor parte de lo que nos pasa o hacemos la olvidamos. Redundantes: un mismo recuerdo, un mismo resultado de comportamiento, se debe en cada caso a incontables circuitos neurales de función semejante o al menos convergente, no necesariamente los mismos cada vez, o más bien cabría decir que es casi imposible que sean los mismos dos veces.

Por otra parte todo recuerdo que contribuye a que digamos algo tal como lo decimos cada vez es "fabricado" en el instante de su actualización, no recuperado de algún almacén. Al producir un recuerdo se mezclan con los elementos anteriores siempre también otros nuevos.

2 Antonio Damasio, Self Comes to Mind. Constructing the Conscious Brain, Pantheon Books, New York 2010. Para lo que sigue cf. también G.M. Edelmann y G. Tononi, A Universe of Consciousness, How Matter Becomes Imagination, Basic Books, New York 2000, y E.R. Kandel, J.H. Schwartz y Th. M. Jessel (eds.), Principles of Neural Sciences, $4^{\text {th }}$ Edition, McGraw Hill 2000, así como E.R.Kandel, En busca de la memoria, Katz Editores, Buenos Aires 2007 
Así que no es que invoquemos de nuevo algo pretérito en nuestra conciencia, sino que lo construimos en cada caso tal como nuestro estado mental en cada momento quiere o puede.

Hablar en un idioma, igual que cualquier otro comportamiento complejo y habitual, consiste en volver a recorrer, o en seguir recorriendo, ciertos circuitos neurales habituales. Ahora bien, todo tipo de circunstancias y eventos ocasionan todo tipo de rodeos por otros circuitos posibles, y si alcanzan la suficiente intensidad, terminan por arrojar cambios tangibles de comportamiento. Es algo que ocurre de continuo. Los circuitos del niño que está aprendiendo a hablar cambian visiblemente de día en día, y luego parece que se van estabilizando, hasta que al final parece que ya no cambian más. Pero sólo lo parece. El que la organización sintáctica del flujo verbal en una persona o grupo de personas parezca constante no quiere decir que en algún lugar de su cerebro se haya acuñado una estructuración definitiva. Las fijaciones son siempre sólo haces de circuitos en curso provisionalmente coincidentes.

Los niños y también los adultos aprenden a hablar constantemente, en el nexo inextricable de todo lo que aprenden en general. Es por ejemplo sabido que en todo proceso de aprendizaje tiene un papel importante la bioquímica emocional, que promueve o no la síntesis de determinadas proteínas y el correspondiente paso de la memoria a corto plazo a la memoria a largo plazo. Nuestra competencia de hablar en cada caso se va modelando así en conexión con las emociones que desencadenan o motivan los comportamientos asociados al hablar y sus consecuencias, y que determinan en una amplia medida la atención y la capacidad de recordar.

Pues bien, desgajar del nexo de toda esta actividad corporal el componente verbal del hablar como si fuese una función autónoma de perfiles precisos parece, a la luz de todo esto, una decisión fuertemente reduccionista. La escritura, que es el principal factor al que debemos la imagen de la autonomía de lo puramente verbal, no es a su vez sino un rendimiento cultural práctico, aunque en verdad ha acuñado decisivamente nuestro imaginario lingüístico.

Claro está que al investigar científicamente los procesos neurales este tipo de reducciones son necesarias. Pero cuando se las aplica no a eventos celulares elementales sino a niveles de gran complejidad, como el de la conceptualización del lenguaje en general, contribuyen a que objetivicemos el lenguaje de un modo muy sesgado, en general bajo la imagen de una competencia fija. Esto supone pasar por alto el hecho de que una parte importante de nuestra actividad mental consiste justamente en buscar y poner a prueba nuevos rendimientos neurales. Esto es algo que se tiene muy en cuenta en las modernas investigaciones sobre el aprendizaje. También nuestra actividad mental adulta ordinaria consiste en una amplia medida en procesos de aprendizaje. Nuestro espíritu es un constante y simultáneo aprender y desaprender.

\section{Fenomenología de la categorización en las descripciones lingüísticas 4.1. Categorizar}

En el curso de los siglos nuestra cultura occidental ha convertido el lenguaje en objeto del pensamiento analítico por medio de formas diversas de categorización, esto es, de subsunción de eventos y objetos singulares bajo pautas de comportamiento cognitivo comunes.

Los seres humanos categorizamos, como todo ser vivo, constante e instintivamente. Nuestra diferencia respecto del resto de la escala evolutiva es la complejidad única de nuestros procesos asociativos. 
Básicamente categorizamos de dos maneras. Unas veces lo hacemos más bien siguiendo el modelo de la simplificación y magnificación de las señales sensoriales en su ruta hacia los centros de control neural, y generamos así pirámides abstractivas de intensión cada vez menor y de extensión cada vez mayor. Un ejemplo clásico es el sistema clasificatorio de Linneo. Es lo que podríamos denominar el "efecto Parménides". Esta forma de categorizar es la que tiene más probabilidades de coincidir de individuo a individuo, ya que reposa sobre todo en la estructura común tanto de los órganos de los sentidos como del procesamiento de las señales sensoriales en los niveles precorticales, y suele conducir a designaciones muy estables.

Otras veces en cambio categorizamos más bien según el modelo de las asociaciones corticales entre sensaciones singulares, así como de éstas con otras sensaciones, con recuerdos y con procesamientos internos más o menos inconscientes, y generamos así lo que me gustaría llamar, por contraste con las pirámides abstractivas, "orientaciones estéticas". La categorización estético-orientativa se deja llevar por la multiplicidad inconsciente de asociaciones internas impredecibles, y construye así formas de percibir las experiencias que pueden rebasar o romper formas anteriores, que cuentan ciertamente con los conceptos abstractivos que cada uno tiene disponibles y con sus designaciones idiomáticas, pero que no se agotan en unos ni otras, sino que, frente a la conceptualidad ya dada, abren espacios de libertad mental y nuevas perspectivas, algo que se expresa sobre todo en formulaciones lingüísticas innovadoras y en ideas nuevas.

\subsection{Analizar}

Lo propio del pensamiento analítico humano por su parte es categorizar y construir objetos en una actitud de distinción entre uno mismo y ellos. Los seres humanos no sólo nos sentimos distintos de nuestro entorno, sino también de nuestras propias sensaciones, percepciones, razonamientos, sentimientos. Esta distinción básica está acuñada instintivamente en la especie humana, y es la responsable de que, a diferencia de los demás animales, dirijamos nuestras capacidades cognitivas a lo que tomamos como el ámbito de los objetos en general, y que comprende absolutamente todo lo identificable fuera y dentro de nosotros. Todo lo que nos representamos de un modo u otro lo consideramos distinto de "nosotros" (yo me siento distinta de mi talla, de mi cerebro y de mis depresiones o euforias). No hablamos de nosotros como de cerebros, sino que hablamos de nuestros cerebros, de un órgano que creemos "poseer". Claro está que somos nuestros cerebros junto con todo lo demás. Pero no nos lo representamos así. También somos nuestro lenguaje y nuestro hablar, pero contemplamos ambas cosas como rendimientos externos, más o menos libres y arbitrarios, de un sujeto distinto de ellos.

Es así como construimos el llamado "sujeto trascendental", como una representación adicional que ha de acompañar a todas las demás y mantenerse distinta de ellas. No podemos remediarlo: tenemos que escindirnos de esta manera. Nuestra especie ha pasado de la cognición directa del entorno en función de la supervivencia en él a una actitud cognitiva universal frente a todo lo conocible, y no tenemos más remedio que dividir, articular y organizar, o sea, analizar, tanto nuestro entorno como a nosotros mismos.

Así que analizar no es en sí mismo una actividad virtuosa. Analizamos en una amplia medida instintivamente, en el medio del idioma que aprendimos, y dando por sentado que nuestras categorizaciones lingüísticas se ajustan a la realidad, tanto en la ciencia como en el cotilleo más trivial. 


\subsection{El análisis lingüístico}

También el trabajo analítico sobre el lenguaje, tanto en lingüística como en filosofía, suele presuponer acríticamente que las palabras con las que categoriza lo lingüístico se corresponden con la realidad a la que intenta referirse, y es así como se construye en cada escuela la representación del lenguaje. Esto implica presuponer como real aquello que se busca, y el procedimiento es circular. Se presupone la existencia de algo que la palabra "lenguaje" identificaría correctamente. Pero sobre todo el analista del lenguaje cree poder analizar éste adecuadamente, por más que lo que pretende analizar queda indeterminado por detrás de su denominación.

Ahora bien, desde el momento en que no sabemos cómo se produce eso que llamamos conciencia (awareness), ese darse cuenta de las cosas y de que uno se da cuenta de ellas, y que todas las teorías que hay actualmente en el mercado sobre la conciencia, la mente y el "self" no son más que modelos tentativos, representaciones construidas por la imaginación de los investigadores, la posibilidad real de delimitar efectivamente el objeto del análisis linguístico ha perdido toda verosimilitud. El componente verbal del hablar se muestra tan densamente interconectado con el conjunto de la corporalidad humana; espíritu y músculo van tan de la mano; hormonas y neurotransmisores, tono y sonido, hablar y callar, significado y gesto, palabra y frase, memoria y emociones, placer y miedo, decir y hacer, acentos e intenciones, yo y mío, actúan tan conjuntamente, que ni siquiera en el plano biológico se los podría separar.

Por eso nuestros intentos de aprehender y entender un presunto lenguaje como tal son inevitablemente de naturaleza especulativa. Ningún modelo positivo del correlato real de la palabra "lenguaje" puede reclamar para sí un fundamento biológico. Pero lo que sí hace la biología es refutar de raíz cualquier pretensión de objetividad epistemológica de cualquier categorización positiva de un "lenguaje en sî".

Así pues nuestra actitud analítica para con nosotros mismos está condicionada biológicamente. Operar ciegamente desde ella conduce a un ingenuo realismo de los conceptos. Pero claro que es posible administrar esa actitud conscientemente y con sentido, o sea, críticamente. La herramienta apropiada para hacerlo es la crítica filosófica del análisis, tal como por ejemplo la desarrolla Hegel en su Ciencia de la Lógica.

\section{Una lingüística humanística con intención pragmática: las condiciones de la posibilidad de una investigación sensata del lenguaje}

No somos seres humanos definitivamente y desde el principio. A lo largo de nuestro desarrollo en la vida nos vamos haciendo más o menos humanos en muy diversos aspectos: más o menos razonables y racionales, más o menos autoconscientes, más o menos comunicativos, capaces de empatía, de expresarnos con soltura, más o menos capaces de juzgar y actuar libremente, más o menos interesados en, y capaces de, evaluar las consecuencias de nuestros actos, etc. En el extremo negativo de estas muchas escalas está la psicopatología sin esperanza, que representa una dramática minoración de la humanidad en el individuo.

Por eso en una perspectiva crítica, tal como Kant la plantea en su muy autoconsciente "Antropología con intención pragmática", la cuestión ya no puede ser fijar teóricamente una presunta condición humana y lingüística universal por vía analítica. Una tarea así sería imposible de cumplir, en primer lugar porque no existe la humanidad como un hecho dado y 
susceptible de descripción, y en segundo lugar porque, si la hubiese, sería una "cosa en sî" a la que no tendríamos acceso cognitivo. Aquí lo único que tiene verdadero sentido es poner la observación analítica al servicio del objetivo de hacer de nosotros en cada caso lo mejor que se pueda. En esto consiste el humanismo de las ciencias humanas. Por eso deberíamos esforzarnos por desarrollar criterios responsables para distinguir en cada caso entre las formas de trabajo que en un determinado campo, aquí el del análisis lingüístico, pueden contribuir a esa mejora, y las que no.

Las ciencias experimentales de la naturaleza, que es de donde la lingüística tomó a partir del siglo XIX su paradigma de la cientificidad, hace ya tiempo que han pasado del análisis de porciones cada vez más pequeñas de la realidad al intento de aprehender la complejidad como una característica emergente de la materia en su conjunto, que no se explica a partir de los componentes singulares en aislado. Esa complejidad, que es la disposición a una autoorganización creciente ("autopoiesis"), parece constituir también el fundamento último de la evolución biológica. La imagen ingenua y muy simplificadora de una ciencia del lenguaje según el modelo de la física o la química clásicas, o incluso de la cibernética, queda así ampliamente desvirtuada. Con las herramientas de un modelo de esa clase ni siquiera podríamos identificar el lenguaje como objeto de un modo aceptable para todos.

Por eso volvemos a tener el lenguaje tal como lo teníamos a comienzos del XIX: como una palabra de nuestra cultura, que sólo puede ser dicha con más o menos sentido y en discursos más o menos sensatos en el marco de esa misma cultura.

Una teoría crítica de la linguística en la actualidad tiene que ser por lo tanto una reflexión sobre las condiciones de la posibilidad de una investigación con sentido en el campo del lenguaje. Esto implica en primer lugar suspender la confianza en la validez ontológica de nuestras categorizaciones; en segundo lugar detectar las equivocaciones que ha generado el reduccionismo en la lingüística que se pretende científica, y tratar de corregirlas desde una perspectiva holística, revisando en cada caso la lógica de la producción ("Entstehungslogik") de cada decisión por referencia al todo, con el fin de distinguir entre simples prejuicios y decisiones bien fundadas; y en tercer lugar, enriquecer nuestra manera de imaginar lo lingüístico tomando en consideración lo que nos van mostrando tanto las ciencias humanas en su conjunto como la investigación biológica, y forzar la imaginación para rebasar las barreras psicológicas que se han ido acumulando en nuestra imagen del lenguaje por causa de las formas usuales de división del trabajo en las instituciones académicas.

Es necesario determinar correctamente la relación de cada investigación singular con una acepción holística del lenguaje. Ahora bien, esto ya no puede querer decir que haya que partir de una imagen de conjunto del lenguaje presuntamente verdadera para luego deducir de ella analíticamente verdades parciales, pues el "lenguaje en sî", como toda cosa en sí, queda fuera del alcance de nuestra capacidad de conocer. Sólo puede querer decir que hay que justificar pragmáticamente todas y cada una de las decisiones reduccionistas por medio de las cuales se constituyen objetos parciales, y que hay que hacerlo por referencia a una fijación general de objetivos, sabiendo que ninguna reducción conceptual puede considerarse como objetivamente adecuada. Mi propuesta es además utilizar como criterio de legitimidad de las decisiones su capacidad o no de contribuir a la mejora de la humanidad en el hombre. 


\section{Apéndice: algunas reflexiones a propósito del abordaje cognitivista de Seven Pinker}

El psicólogo experimental y cognitivista Steven Pinker publicó en 1994 un libro con el título "The language instinct: how mind creates language", que ha tenido una enorme repercusión entre los lingüistas de todo el mundo porque sus tesis se han presentado como resultado de investigaciones empíricas tanto neurocientíficas como psicológicas. Con posterioridad a esta publicación Pinker ha retomado el tema del lenguaje en muchas otras más recientes, pero sus tesis básicas no se han modificado, y él mismo remite de continuo a esta primera obra. No voy a hacer aquí una crítica sistemática de la misma: dejo esta tarea para otra ocasión. Sólo quisiera mencionar brevemente algunas de las tesis que él mismo presenta como centrales, y arrojar sobre ellas el tipo de crítica en la que consiste este "teoría crítica de la lingüística".

Pinker defiende que el lenguaje es un instinto como los demás, y no un hecho o producto cultural, y parte de una serie de presuntas evidencias que no se someten a verificación, y que componen en esencia el siguiente cuadro de conjunto:

El lenguaje es un comportamiento instintivo, que se desarrolla sin conciencia de su lógica subyacente, y que consiste en la habilidad de juntar palabras en frases. Es cualitativamente igual en todos los individuos, es distinto de habilidades más generales de procesar información y de comportarse inteligentemente, y lo gobierna un módulo cerebral propio. Los seres humanos nacen con una gramática universal consistente en diseños preliminares para las reglas gramaticales, que hacen a los seres humanos capaces de inferir las reglas generativas correctas del lenguaje a partir de un input defectuoso. El pensamiento no es lo mismo que el lenguaje ni depende de él. Hay mucho pensamiento sin palabras y sin lenguaje.

Los idiomas históricos concretos no son sino proyecciones específicas de un "lenguaje universal del pensamiento", el "mentalés". Hablar es traducir del mentalés a un idioma existente, y entender es el proceso inverso. Hay una "estructura sintáctica profunda", que debe de ser básicamente la misma en todos los idiomas y constituye la "anatomía común" de las frases de todos los idiomas. En el habla se la genera "antes" de implementarla con palabras, y al entender se la recupera mediante análisis morfo-sintáctico (parsing). Las relaciones entre los nódulos del árbol reflejan relaciones entre las ideas en mentalés.

El cerebro de cada uno contiene un diccionario de palabras y de los conceptos por los que están éstas (un diccionario mental), así como una serie de reglas para producir relaciones entre conceptos (una gramática mental). Las palabras poseen significados estables. Todos los idiomas tienen nombres, verbos, auxiliares, casos, concordancia, etc,. Estas son categorías lingüísticas universales. Al hablar se encodifican cadenas de símbolos discretos bajo la forma de una corriente continua de sonido (conversión de digital a analógico), y al entender se produce el proceso inverso. El entender se guía sobre todo por la acústica, no por expectativas de significado.

La variación neural y genética de un individuo a otro en lo que atañe al lenguaje tiene que ser sólo cuantitativa y mínima. Gracias a la selección natural todas las personas normales han de ser cualitativamente iguales. Desde el momento en que existe un diseño mental único que subyace a todas las lenguas, todos tenemos las mismas mentes y hablamos en el fondo el mismo lenguaje.

Un aspecto formal que llama la atención en el discurso de Pinker es su constante transición de proposiciones tipo "debería haber tal o cual" a "tiene que haber tal o cual" y finalmente a "hay tal o cual", sin que medie investigación empírica que verifique lo correcto del paso de la conjetura a la aserción de un hecho. Es paradigmática a este respecto su famosa tesis del "mentalés", un presunto "lenguaje-máquina" universal del cerebro humano que se empieza presentando como "the following picture":

People $d o$ not think in English or Chinese or Apache; they think in a language of thought. This language of thought probably looks a bit like all these languages; presumably it has symbols for concepts, and arrangements of symbols that correspond to who did what to whom, as in the paint-spraying representation 
shown above. But compared with any given language, mentalese must be richer in some ways and simpler in others.

Sigue contando lo que el mentalés tiene que ser o contener, y de pronto concluye que "knowing a language $i s$, then, knowing how to translate mentalese into strings of words and viceversa". A partir de aquí Pinker da por sentado y considera demostrado que el mentalés existe.

Sin entrar en demasiados detalles: Pinker adopta el reduccionismo chomskiano extremo de definir el lenguaje como la capacidad de juntar palabras en frases, así como la conjetura indemostrada de que llevamos "hardwired" una cierta gramática universal, y que construimos a partir de ella una gramática idiomática de reglas fijas y un diccionario de significados estables. Intenta distanciar la linguiística de las ciencias humanas y culturales afirmando que el lenguaje es un instinto y debe ser estudiado como tal, aunque luego no ejecuta este programa etológico. No podría hacerlo porque previamente ha aislado la habilidad de juntar palabras en frases respecto del conjunto del comportamiento del que es parte el flujo verbal. El libro no es una etología humana focalizada en el lenguaje, sino una recopilación de dogmas de la Gramática Generativa complementada con algunas informaciones neurológicas que sin embargo nunca se ponen en relación directa con lo que se supone que deberían apoyar o confirmar.

Pero al autor le importa sobremanera que se le crean una serie de cosas: que el lenguaje es distinto e independiente del resto de las funciones cognitivas y neurales en general; que es esencialmente el mismo en todas partes y en todos los individuos; que su plan general está inscrito en nuestro código genético y en la circuitería neuronal; que las estructuras sintácticas son independientes de los significados de las palabras que ensamblan, y en el hablar se generan al margen de ellos; y que los seres humanos somos parecidísimos los unos a los otros, en particular en todo lo que tiene que ver con nuestro lenguaje. La pregunta es: ¿por qué esta pasión por ideas tan frontalmente opuestas tanto a la experiencia fenoménica de la que nos ocupamos los lingüistas como a lo que positivamente están descubriendo los neurocientíficos sobre nuestros cerebros?

El abordaje de Pinker intenta homologar a los seres humanos y su instinto lingüístico con el resto de los animales que la zoología estudia científicamente y sin conflictos epistemológicos. En su perspectiva no cabe la consideración de lenguajes enriquecidos o empobrecidos ni por lo tanto crítica alguna a los factores inhibidores de la individualidad humana y su lenguaje. No caben tampoco perspectivas teóricas alternativas, ya que todas son para él prehistoria oscurantista. No hay espacio para las diferencias entre discursos individuales, ni siquiera entre formas más y menos exigentes de expresión lingüística. Pinker descarta como trivial todo lo que distingue entre ideas y textos mejores o peores, de modo que para él las cosas están bien como están. Su enfoque se revela así contrario a toda forma exigente de humanismo, y extremadamente ingenuo a la hora de calibrar la licitud epistemológica de su propio discurso.

De cara a los gravísimos problemas lingüísticos reales en nuestro mundo actual, problemas de comunicación entre culturas e individuos, de insuficiente capacidad de articular una expresión rica para lo que son las exigencias laborales y sociales de nuestro mundo, un abordaje de esta clase resulta totalmente impotente para siquiera identificar los problemas, no digamos resolverlos. El fallo está en el rechazo de la perspectiva integral, holística, y la asunción de un reduccionismo presuntamente científico con el que se bloquea toda forma de crítica epistemológica. 